\title{
AMENDMENTS
}

\section{Author Correction: Performance assessment of DNA sequencing platforms in the ABRF Next-Generation Sequencing Study}

Jonathan Foox, Scott W. Tighe (iD, Charles M. Nicolet, Justin M. Zook D, Marta Byrska-Bishop (D), Wayne E. Clarke, Michael M. Khayat (D), Medhat Mahmoud D, Phoebe K. Laaguiby, Zachary T. Herbert D, Derek Warner, George S. Grills, Jin Jen, Shawn Levy D , Jenny Xiang, Alicia Alonso, Xia Zhao, Wenwei Zhang, Fei Teng (iD, Yonggang Zhao,

Haorong Lu (D), Gary P. Schroth D, Giuseppe Narzisi D, William Farmerie (D), Fritz J. Sedlazeck (D), Don A. Baldwin (D) and

Christopher E. Mason (D)

Correction to: Nature Biotechnology https://doi.org/10.1038/s41587-021-01049-5, published online 9 September 2021.

In the version of this Article initially published, Extended Data Fig. 4 had incorrect coloration and an incorrect legend. PacBio long reads matched against CLINVAR variants were incorrectly colored in light green instead of brown (top right of panel a). In the bottom shared legend (below panel c), Nanopore was incorrectly identified with a brown circle instead of dark green. This figure has been corrected with a new legend for CLINVAR/OMIM variant analysis (below panel b) and a separate, corrected legend for exam variant analysis at the bottom of the figure.

The online version of the article has been updated.

Published online: 11 October 2021

https://doi.org/10.1038/s41587-021-01122-Z

(c) The Author(s), under exclusive licence to Springer Nature America, Inc. 2021

\section{Author Correction: An injectable bone marrow-like scaffold enhances T cell immunity after hematopoietic stem cell transplantation}

Nisarg J. Shah D, Angelo S. Mao, Ting-Yu Shih, Matthew D. Kerr, Azeem Sharda, Theresa M. Raimondo, James C. Weaver, Vladimir D. Vrbanac, Maud Deruaz D, Andrew M. Tager, David J. Mooney (D) and David T. Scadden

Correction to: Nature Biotechnology https://doi.org/10.1038/s41587-019-0017-2, published online 11 February 2019

In the version of this Article initially published, Fig. $2 \mathrm{~d}$ displayed a mistaken image. The original Fig. $2 \mathrm{~d}$ panel has now been replaced with the correct image. The original and corrected Fig. $2 \mathrm{~d}$ images are shown below. This change has been made to the online version of this Article.
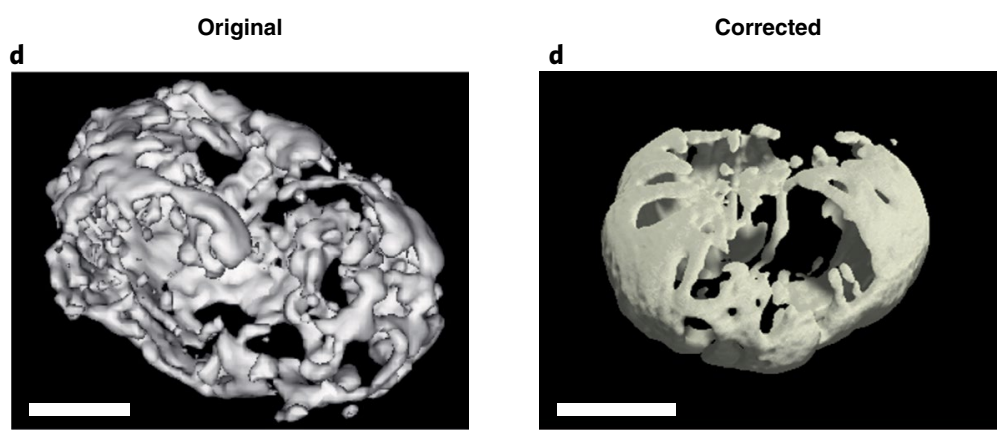

Fig. 2 | Original and Corrected.

Published online: 18 October 2021

https://doi.org/10.1038/s41587-021-01081-5

(C) The Author(s), under exclusive licence to Springer Nature America, Inc. 2021 